\title{
STUDY OF OPEN URETEROLITHOTOMY VERSUS ENDOSCOPIC URETEROLITHOTOMY FOR THE MANAGEMENT OF URETERIC CALCULI
}

Vikas Chalotra ${ }^{1}$, Sunil Shukla², Amritpal Singh Rana ${ }^{3}$, Aman Bharti', Dhruvendra Lal ${ }^{5}$

${ }^{1}$ Assistant Professor, Department of Surgery, GGSMCH, Faridkot, Punjab, India.

${ }^{2}$ Senior Resident, Department of Surgery, RML, Lucknow, Uttar Pradesh, India.

${ }^{3}$ Associate Professor, Department of Surgery, GGSMCH, Faridkot, Punjab, India.

${ }_{4}^{4}$ Assistant Professor, Department of Medicine, GGSMCH, Faridkot, Punjab, India.

${ }^{5}$ Senior Resident, Department of Community Medicine, CMC, Ludhiana, Punjab, India.

\section{ABSTRACT}

\section{BACKGROUND}

Ureteric stones are most commonly treated nowadays by endoscopic methods. Open surgery has limited role in the treatment of ureteric calculi.

\section{MATERIALS AND METHODS}

This study was done to compare open ureterolithotomy and rigid ureteroscopy for the treatment of ureteric calculi. In this study, 30 patients were divided into two groups of 15 each. Study was done to compare open ureterolithotomy and rigid ureteroscopy for the parameters like per operative complications, post-operative complications, delayed complications, ambulation, post-surgery hospital stay and duration of surgery.

\section{RESULTS}

Rigid ureteroscopy was superior to open ureterolithotomy for parameters like ambulation, post-surgery hospital stay, postoperative pain complications and duration of surgery.

\section{CONCLUSION}

Rigid ureteroscopy is superior to open ureterolithotomy.

\section{KEY WORDS}

Ureteric Calculi, Open Ureterolithotomy, Endoscopic Ureterolithotomy.

HOW TO CITE THIS ARTICLE: Chalotra V, Shukla S, Rana AS, et al. Study of open ureterolithotomy versus endoscopic ureterolithotomy for the management of ureteric calculi. J. Evolution Med. Dent. Sci. 2019;8(09):613-621, DOI: $10.14260 /$ jemds/2019/136

\section{BACKGROUND}

Urinary stone disease is the third most common affliction of the urinary tract, exceeded only by urinary tract infections and pathologic conditions of the prostate (BPH and prostate cancer). The life time recurrence rate is approximately $50 \%$. Men are affected 2 to 3 times more frequently than women.1-3 Incidence of urinary stone disease is relatively uncommon before the age of 20 but peaks in the fourth to sixth decades of life. 4

\section{Aim of The Study}

Aim of this study is to compare the open ureterolithotomy with endoscopic ureterolithotomy.

'Financial or Other Competing Interest': None.

Submission 24-10-2018, Peer Review 12-02-2019,

Acceptance 19-02-2019, Published 04-03-2019.

Corresponding Author:

Dr. Dhruvendra Lal,

Senior Resident,

Department of Community Medicine,

CMC, Ludhiana,

Punjab, India.

E-mail:drdhruvlal@gmail.com

DOI: $10.14260 /$ jemds $/ 2019 / 136$

The comparison shall be done as per following parameters-

- Duration of surgery (in minutes),

- Pre-operative complications,

- Post-operative complications,

- Ambulation,

- Total hospital stay after operation (in days),

- Delayed complications.

\section{MATERIALS AND METHODS}

The non-randomized control trial study of Thirty adult patients of both sexes admitted in surgical department of Guru Nanak Dev Hospital/Govt. Medical College, Amritsar (Punjab) between 1/1/2013 to 30/6/2014 were included in the study (time frame).

These patients received two modalities of surgical treatment (Open Ureterolithotomy versus Endoscopic Ureterolithotomy, 15 patients in each), which were allocated into two modalities (taking into account the feasibility, every alternate case was allotted each modality of treatment) and outcome of which were compared in terms of duration of surgery (in minutes), pre-operative complications, postoperative complications, ambulation, total hospital stay after operation (in days) and delayed complications. 


\section{Inclusion Criteria}

Thirty adult (More than 14 years) patients from both sexes admitted in surgical department who gave consent to participate.

\section{Exclusion Criteria}

Any patient of endoscopic converted to open ureterolithotomy due to any intraoperative complication was excluded from the study.

\section{Instruments Used}

The instruments used were rigid ureteroscopy set 8/9.8 Fr, 12-degree, double working channel, cystoscope 19.5 French, telescope 30-degree, pneumatic lithotripsy set, standard laparoscopic unit.

Patients were followed after surgery for post-operative complications and were followed for 3 months for any delayed complication. The results were expressed as percentages, frequencies and Chi-square test \& Fisher's test was used to find the significance of difference between the two groups at $95 \%$ confidence interval.

\section{RESULTS}

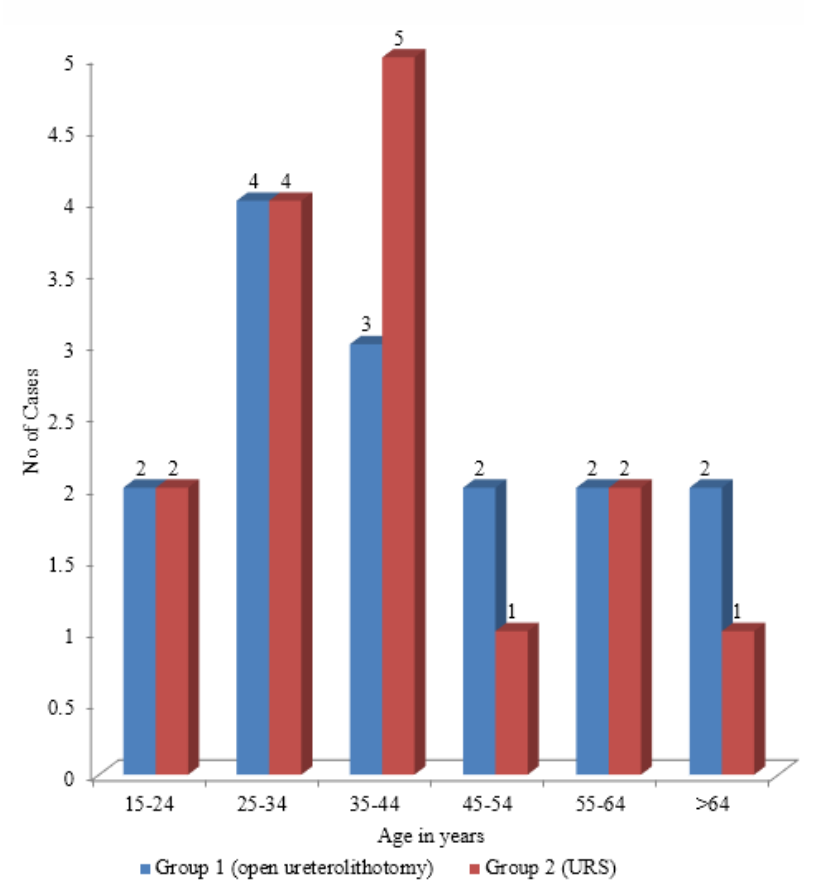

Figure 1. Age Incidence Distribution

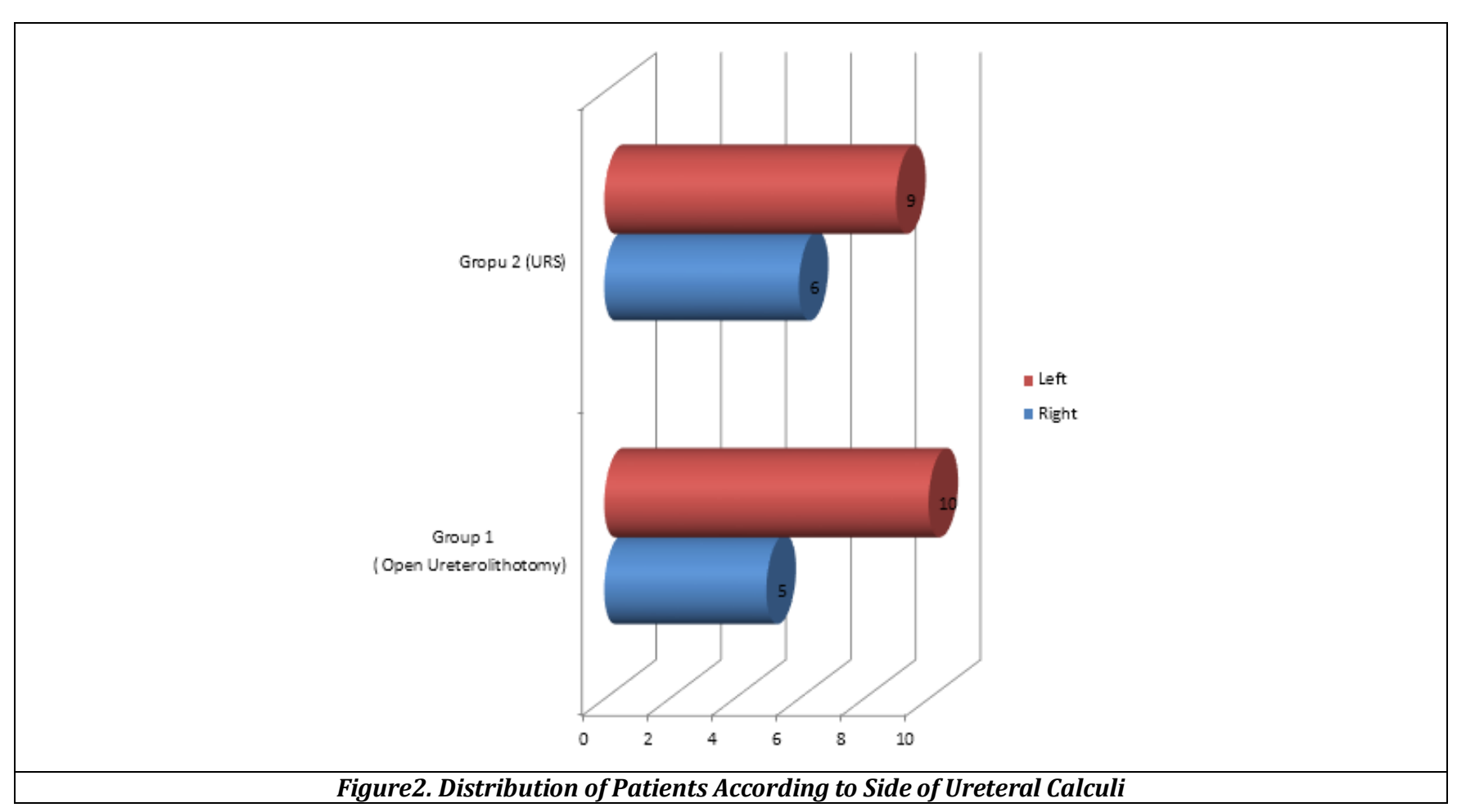






Figure 3. Stone Location Distribution



Figure 4. Distribution of Patients According to Ambulation

It was found that maximum patients in Group 1 i.e. 54\% were ambulatory in 49-60 hours after surgery, 33\% patients were ambulatory in 37-48 hours and 13\% were ambulatory in 25-36 hours after surgery whereas in Group 2, 2 patients were excluded from the study as they were converted to open ureterolithotomy and the remaining 13 patients i.e. $100 \%$ were ambulatory in 13 24 hours after surgery. 


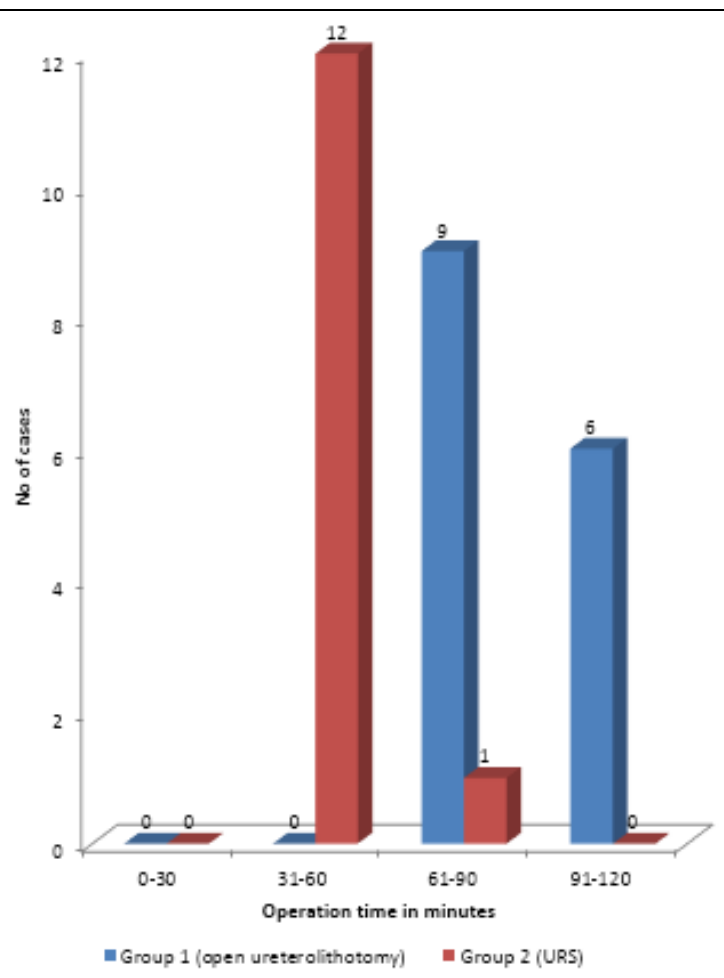

Figure 5. Distribution of Patients According to Duration of Surgery

In Group 1, 60\% of patients had their surgery completed in 61-90 minutes and 40\% had their surgery completed in 91-120 minutes whereas in Group 2, 12 patients out of remaining 13 patients i.e., 93\% patients had surgery completed in 31-60 minutes and $7 \%$ patients had surgery completed in $61-90$ minutes.

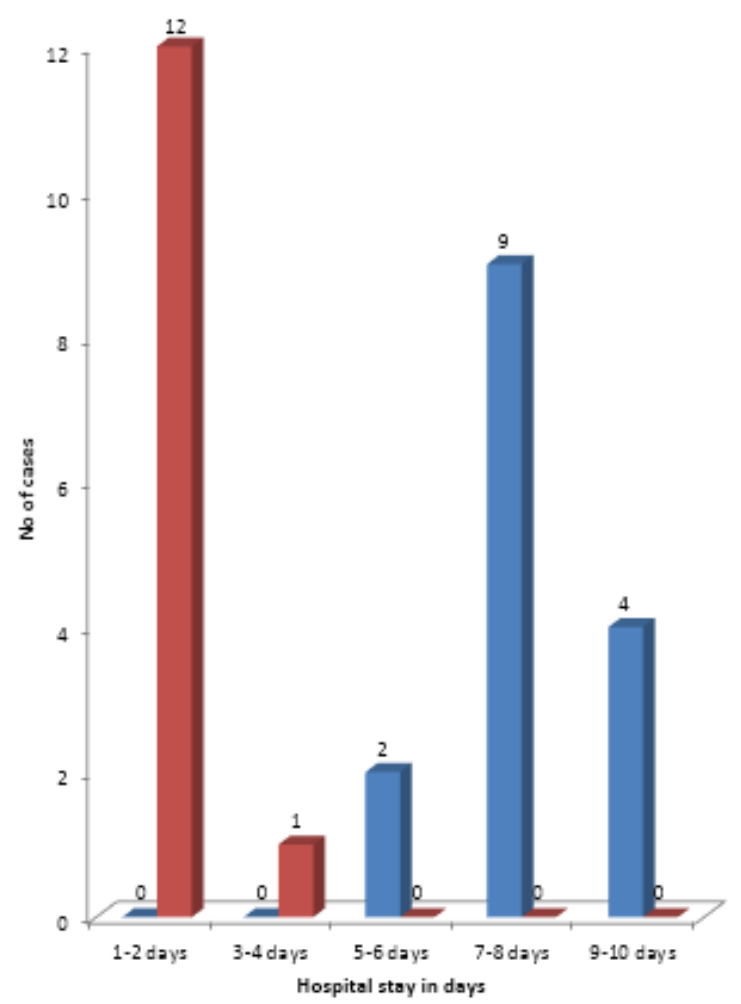

Figure 6. Distribution of Patients According to Duration of Hospital Stay After Surgery

$60 \%$ of patients of group a has hospital stay between 7 to 8 days after surgery, 27\% 9-10 days after surgery and $13 \%$ between 5-6 days after surgery whereas in

Group 2, 13 patients i.e. 92\% patient had hospital stay between 1-2 days after surgery and 8\% had hospital stay between 3-4 days after surgery 
As p-value is $<0.001$ duration of hospital stay after surgery was not comparable in both the groups and the difference was highly significant with patients in group 2 having shorter hospital stay after surgery.



Figure 7. Distribution of Patients According to Per-Operative Complications

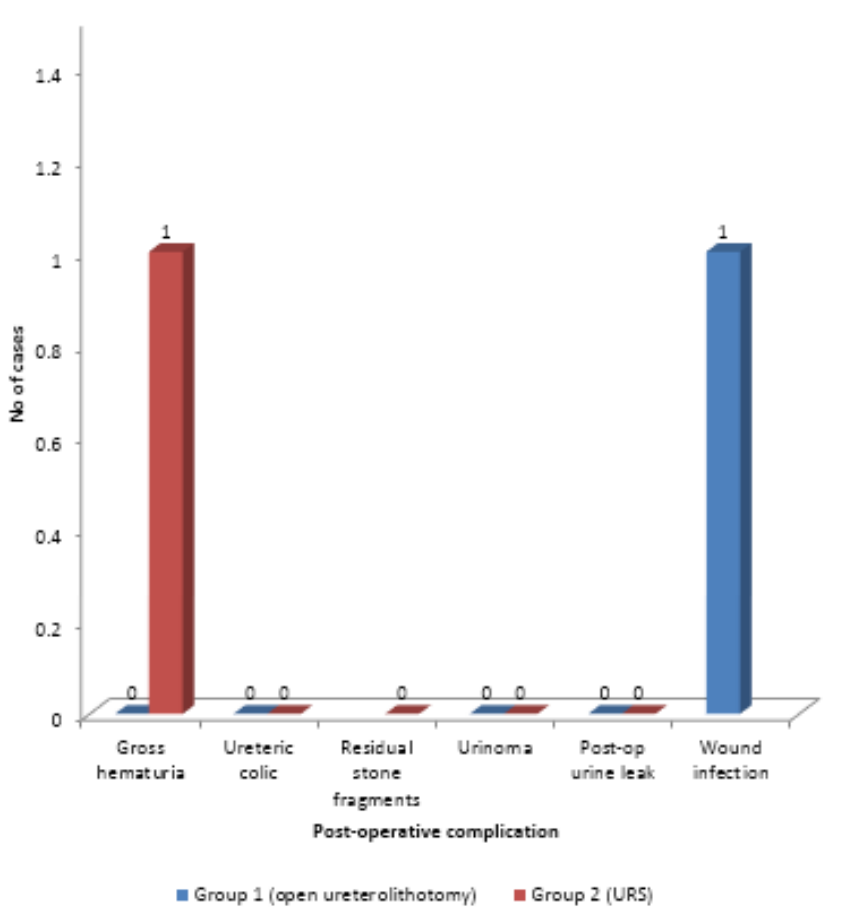

Figure 8. Distribution of Patients According to Post Operative Complications

Group 1 had 1 patient with per operative complication out of total 15 patients whereas Group 2 had total 2 patients with per operative complications as the patients with bleeding and mucosal injury were converted to open ureterolithotomy out of total 15 patients. As p-value>0.05 two Groups were comparable in per operative complications with no significant difference.

Gross hematuria was present as a post-operative complication in 1 out of 13 patients in the study in Group 2 and absent in Group 1. As p-value was $>0.05$ (0.274), gross hematuria was comparable in two groups. Wound infection was present in 1 patient in group 1. Wound infection was not comparable as it is not a complication of URS because there is no wound in URS. 


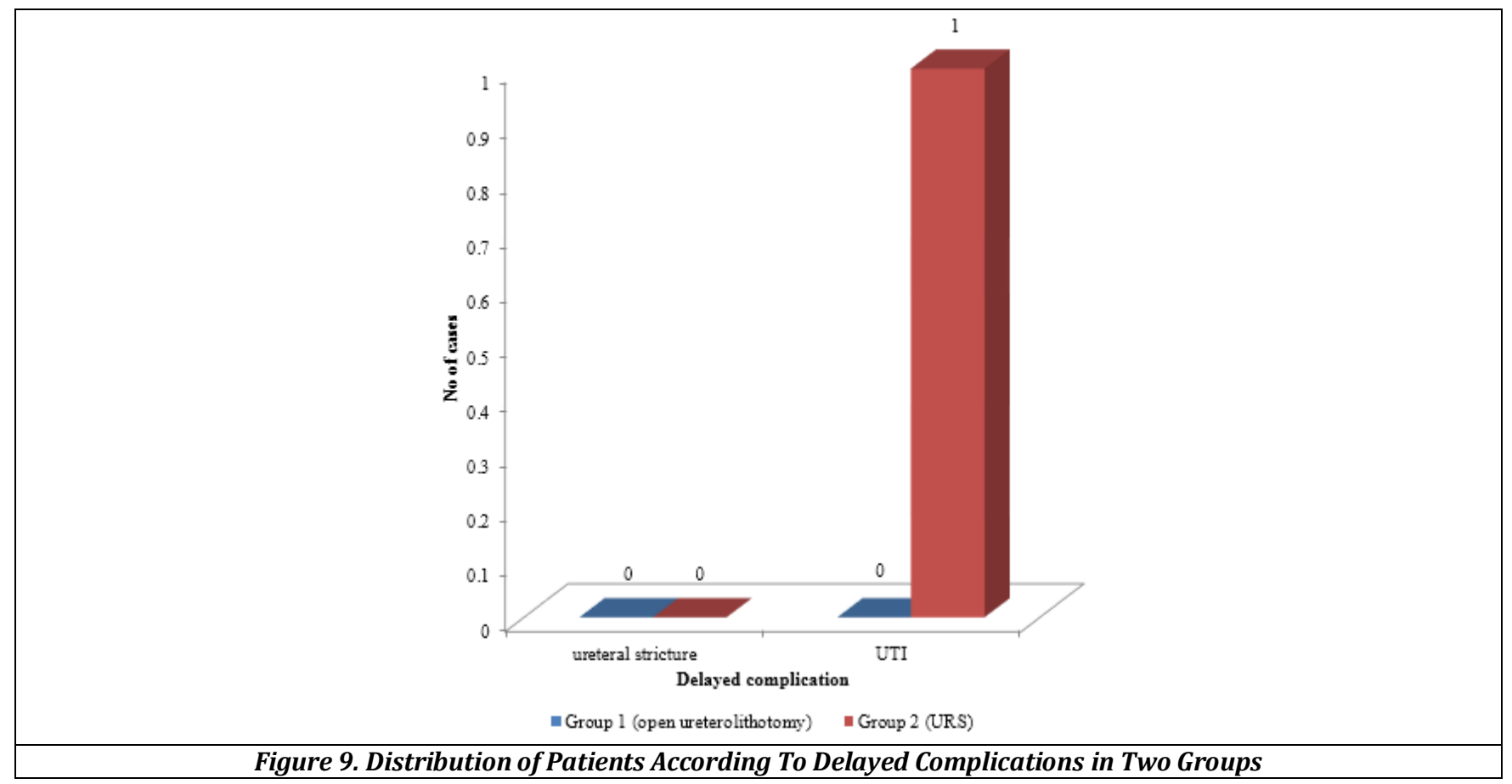

Ureteral stricture was absent in both the groups. UTI was a delayed complication in 1 patient in Group 2 out of 13 patients with 2 patients excluded from the study due to conversion to open surgery.

None of the patient out of 15 patients in Group 1 had delayed complication whereas 1 patient out of 13 total patients in Group 2 had delayed complication. As p-value was $>0.05$ (1) two groups were comparable in delayed complications with no significant difference.

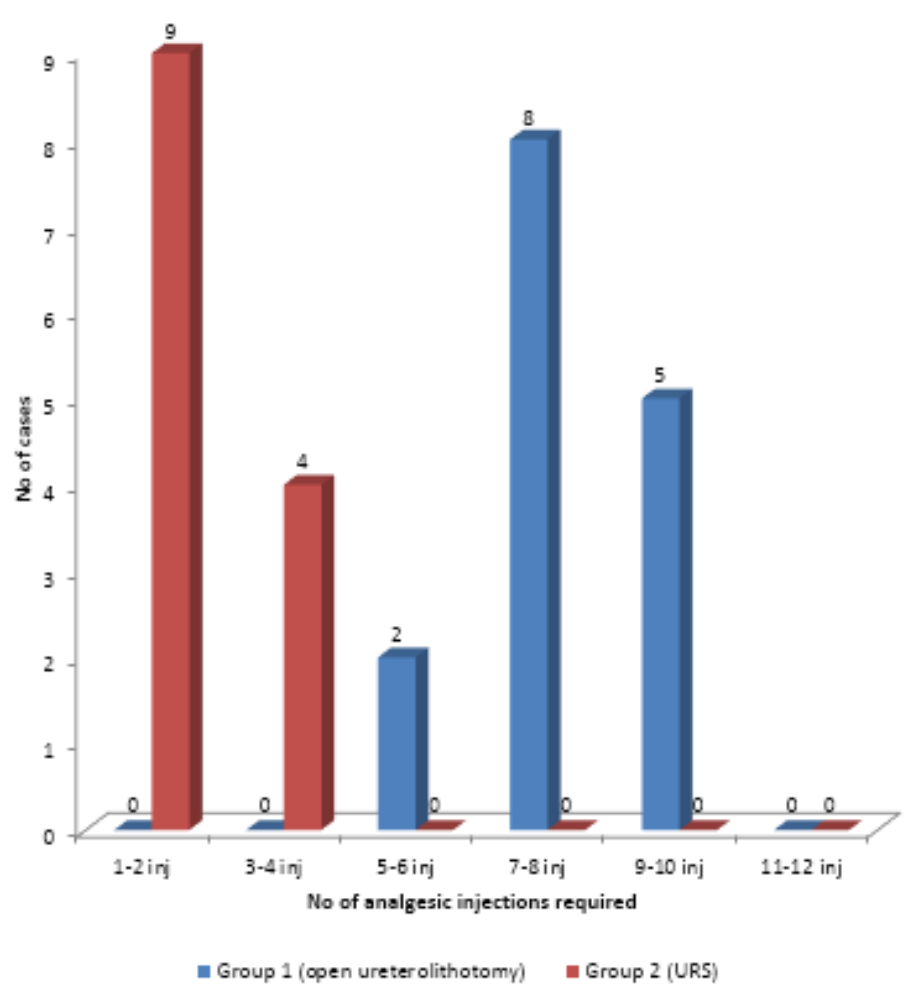

Figure 10. Distribution of Patients According to Post-Operative Pain (no. Of Post-Operative Analgesic Injection Required)

In group 1, 54\% patients required 7-8 analgesic injections post operatively, 33\% patients required 9-10 analgesic injections and 13\% patients required 5-6 analgesic injections post operatively whereas in Group 2, 13 patients i.e. 70\% required 1-2 analgesic injections post operatively and 30\% patients required 3-4 analgesic injections.

As p-value was $<0.001$, difference in post-operative pain was highly significant in both the groups with Group 2 patients requiring fewer analgesic injections post operatively. 


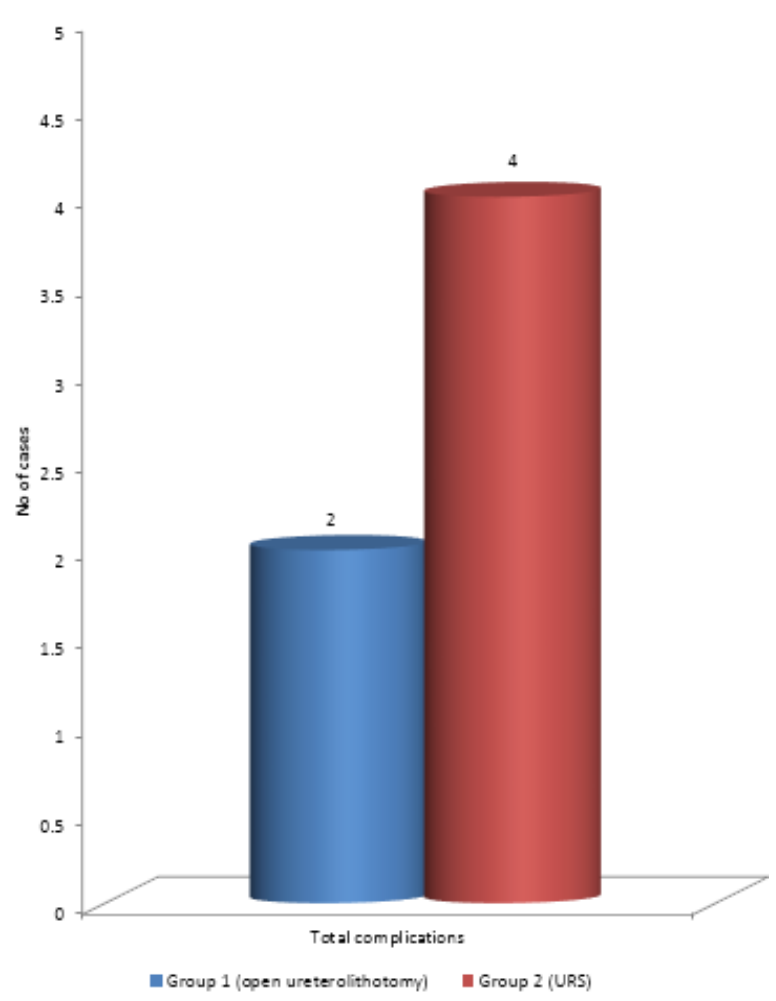

\section{Figure 11. Distribution of Patients According to Total Complications}

Our study showed that in Group 1, 35\% stones were located in upper third of ureter, $20 \%$ stones were located in middle third and $45 \%$ stones were located in lower third of ureter whereas in Group 2, 27\% stones were located in upper third of ureter, 33\% stones were located in middle third and $40 \%$ stones were located in lower third of ureter. As p-value is $>0.05$, stone location is comparable in both groups.

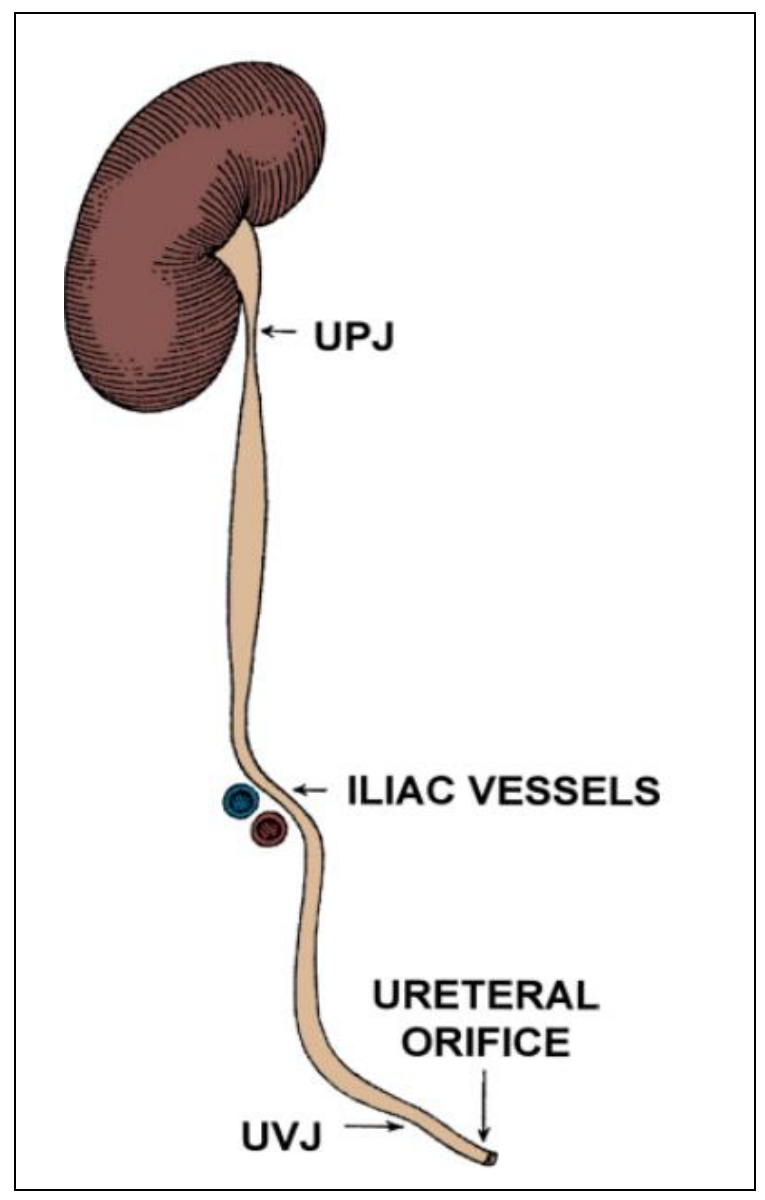




\section{DISCUSSION}

The first ureteroscopy was performed in 1912 by Hugh Hampton Young in a patient with posterior urethral valves when a rigid cystoscope was advanced into the dilated ureter (Young and McKay, 1929). 5 In 1960s a rudimentary ureteroscope was placed into a ureter through a ureterolithotomy during open surgery (Marshall, 1964). ${ }^{6}$ Initially, all ureteroscopes were rigid in design and consisted of a rod-lens system with outer diameters ranging from 12 to $13.5 \mathrm{Fr}$. These endoscopes required routine dilation of the ureter in order to gain access as well as an indwelling stent postoperatively. By the mid-1980s, improvements in design and engineering had resulted in miniaturization of ureteroscopes and a corresponding decrease in trauma

associated with the procedure. Rigid endoscopes were reduced to $8.5 \mathrm{Fr}$ in diameter and contained a working channel.

Georgescu et al, 7 conducted a study in which 8150 semirigid ureteroscopic procedures for ureteral lithiasis were performed in 7456 patients. Intraoperative incidents occurred in 348 cases. The overall rate of intraoperative complications was (228 cases). These were represented by lesions of the ureteral mucosa (139 cases), perforation (58 cases), bleeding (16 cases), ureteral avulsion (3 cases) and extra-ureteral stone migration (12 cases). In our study, intraoperative complications were encountered in ( 2 cases). In one case bleeding was the complication seen, and other one had mucosal injury. Both of these cases were converted to open ureterolithotomy. None of the cases were complicated by perforation of ureter, avulsion of ureter, or by stone retropulsion.

Analysis of literature revealed a stone free rate of $81 \%$ for URS treatment of proximal ureteric stones. ${ }^{8}$ In a study conducted by Dhinakar $L, 9$ the success rates for stone clearance of lower ureteric stones was over $90 \%$. The success rate of stone clearance dropped to around $70 \%$ when ureteroscopy was done for proximal stones. In our study out of 4 stones located in upper ureter only 1 stone was not removed by rigid ureteroscopy and converted to open ureterolithotomy. There was $75 \%$ success rate for stones in upper third of ureter. In the middle ureter, in 1 case the stone was not removed out of 5 cases in middle ureter. There was $80 \%$ success rate for rigid ureteroscopy for stones located in middle ureter. In the lower third of ureter there was $100 \%$ success rate for stone removal by rigid ureteroscopy. There was overall $86.67 \%$ success rate for ureteral calculi located in any location in ureter for rigid ureteroscopy whereas it was $100 \%$ for open ureterolithotomy.

A paper by Ather et al,10 assessing the outcome, 195 patients with primary ureteric stones reported that the endoscopic method had a higher complication rate of $32 \%$ compared to the open method, which had a rate of $13 \%$. In our study the rigid ureteroscopy had complication rate of $26.67 \%$ as compared to open method, which had a rate of $13.33 \%$. As p-value $>0.05$, the difference in total complication rate was not significant between two groups.

Saeed ${ }^{11}$ conducted a study comparing ureteroscopy using pneumatic lithotripsy with open surgery (ureterolithotomy) in treating ureteric stones regarding the success rate, procedure time, need for post-operative analgesia, duration of hospital stay, and complications rate. Fifty patients were treated by ureteroscopy and 40 patients by ureterolithotomy. Their age and sex distribution was comparable. Results of both treatment modalities were analysed and compared. The success rate for ureteroscopy was $90 \%$ and for ureterolithotomy was $97.5 \%$. The procedure time was significantly shorter for ureteroscopy patients (42 minute versus 74 minute). Mean post-operative analgesia was much less for ureteroscopy (1.1 versus 9.5 analgesic injections). Ninety two were discharged at same day of operation with mean hospital stay of 1.12 days compared to 3.5 days for ureterolithotomy group. Complications were reported in $16 \%$ in ureteroscopy and $8 \%$ in ureterolithotomy.

In our study there was success rate of $86.67 \%$ for ureteroscopy and for ureterolithotomy it was $100 \%$. The procedure time was significantly shorter for ureteroscopy (53 minute versus 89 mints). Mean post-operative analgesia was much less for ureteroscopy (3 versus 7.7 analgesic injections). p-value $<0.001$. Mean hospital stay was much less for ureteroscopy (2.2 versus 7.7 days). Total complications reported were $26.67 \%$ in ureteroscopy and $13.33 \%$ in open ureterolithotomy. In our study the mean ambulation of the patients was 47.8 hours after open ureterolithotomy and 21.87 hours after rigid ureteroscopy for ureteric calculi as the patients in both the groups were operated under spinal anaesthesia. It showed ambulation was much earlier in patients with rigid ureteroscopy,

In our study patients were followed for 3 months after rigid ureteroscopy, $7.69 \%$ (1 case) had UTI as delayed complication.

\section{Limitation}

The sample size in each treatment modality (15 in each group) was less because of the time constraint and availability of patients.

\section{CONCLUSION}

Endoscopic treatment with rigid ureteroscope was found safe to use and effective in management of ureteral calculi at all the locations of stone in ureter with no significant difference in stone removal rate for lower and middle ureteral calculi than open ureterolithotomy. Endoscopic treatment with rigid ureteroscope differs significantly in stone removal rate for upper ureteral calculi than open ureterolithotomy with open ureterolithotomy being better for upper ureteral calculi.

Endoscopic treatment with rigid ureteroscope was found to be effective in reducing post-surgery hospital stay, postoperative pain complications, patients were ambulatory much earlier as compared to patients who underwent open ureterolithotomy for ureteral calculi.

Patients treated with rigid ureteroscope for ureteral calculi were found to have shorter operating time as compared to open ureterolithotomy. But no significant difference in total complication rate was seen as compared to open ureterolithotomy.

Endoscopic treatment with rigid ureteroscope is comparable to open ureterolithotomy with no statistical difference with respect to per operative, post-operative and delayed complication rate for the treatment of ureteric calculi. This study appears to show more favourable results with endoscopic treatment with rigid ureteroscope than for open ureterolithotomy. 


\section{REFERENCES}

[1] Hiatt RA, Dales LG, Friedman GD, et al. Frequency of urolithiasis in a prepaid medical care program. Am J Epidemiology 1982;115(2):255-65.

[2] Pearl MS, Calhoun EA, Curhan GC, et al. Urological diseases in America project: urolithiasis. J Urol 2005;173(3):848-57.

[3] Moe OW. Kidney stones: pathophysiology and medical management. Lancet 2006;367(9507):33344.

[4] Frabboni R, Santi V, Ranchi M, et al. In situ echoguided extracorporeal shock wave lithotripsy of ureteric stones with the Dornier MPL 9000: a multicentric study group. Br J Urol 1994;73(5):48793.

[5] Young HH, McKay RW. Congenital valvular obstruction of the prostatic urethra. Surgery Gynecology \& Obstetrics 1929;48:509-12.

[6] Marshall VF. Fiber optics in urology. The Journal of Urology 1964;91:110-6.
[7] Georgescu D, Multesu R, Geavlete B, et al. Intraoperative complications after 8150 semirigid ureteroscopies for ureteral lithiasis: risk analysis and management. Bucharest, Romania, 1990;109(3):369-74.

[8] Preminger GM, Tiselius HG, Assimos DG, et al. 2007 Guidelines for the management of ureteral calculi. J Urol 2007;178(6):2418-34.

[9] Dhinakar L. A retrospective study of ureteroscopy performed at the sultan Qaboos hospital, salalah from august 2001 - august 2006. Oman medical Journal 2007;22(3):24-32.

[10] Ather MH, Paryani J, Memon A, et al. A 10-year experience of managing ureteric calculi: changing trends towards endourological intervention--is there a role for open surgery? BJU Int 2001;88(3):173-7.

[11] Saeed NH. Ureteric stone management: comparative study of ureteroscopy using pneumatic lithotripsy with open ureterolithotomy results. Ann Coll Med Mosul 2013;39(1):70-4. 